\title{
Brand Equity Valuation: an Optimized Interbrand Model which is Based on the Consumer Perspective
}

\author{
Yizheng Jia \\ School of Economic and Management,Beijing Jiaotong \\ University,Beijing,China. \\ jiayizhengqq@163.com
}

\begin{abstract}
Because of the concept of the brand equity is defined ambiguously in the scientific literature and defined from different perspectives, there are a variety of methods. The goal of the paper is to build an optimized Interbrand model which is based on the consumer perspective of brand equity. In this paper, by analyzing the Interbrand brand equity evaluation model and finding the defect of the model, we constructed a comprehensive model of brand equity evaluation which we believe is capable of both estimating the brand equity more accurately and showing the sources of brand equity, and then, taken Haier brand as an example to make an empirical analysis of the optimized model. The empirical result show that the evaluation of results compares to the Interbrand model is more objective and comprehensive.
\end{abstract}

Keywords-brand equity evaluation; the Interbrand model; an optimized model

\section{INTRODUCTION}

Brand equity as a special kind of intangible assets of the enterprise, it not only can create value for customers, but also play a very important role in securing long-term commercial success and creating sustainable competitive advantages in the marketplace[1].So, that is why it is great significance and necessary for the enterprise to have a deep understanding of brand concept and to develop a reasonable method of brand equity evaluation.

However, there is little consensus on the concept of brand equity, although there are numerous conceptualizations for brand equity in the literature. The diversity of its definitions in the literature may be due to the different understanding of this intangible asset, just like the fable of blind men and elephant[2], and in turn various approaches estimate the overall value of a brand from different perspectives and for different purposes (e.g. merger, acquisition, or divestiture). By review the previous study of brand equity evaluation, we can see that the method was proposed from two main perspectives. The first perspective is financially based. The second perspective is customer-based perspective. Each perspective, however, takes a one-sided vision on the concept of brand equity and the source of brand value.

This study attempts to construct a new model which was tested by theoretical and empirical analysis. And, the paper can fall into four sections. The first section, the evaluation

\author{
Wensong Zhang \\ School of Economic and Management,Beijing Jiaotong \\ University,Beijing,China. \\ wensongzhang@sohu.com
}

models of brand equity which are based on different perspectives will be presented and analyzed. The next section, we give a brief introduction of the Interbrand model. The following section, we proposed an optimized model which provides a more comprehensive from consumer perspective. We believe the new model is capable of both estimating the brand equity more accurately and showing the sources of the equity. In the final section, we take Haier brand as an example to make an empirical analysis of the optimized model and give the conclusion of this paper.

\section{LITERATURE REVIEW}

As for the brand valuation model, different organizations or persons view the brand equity from different perspectives and build the method for the different purposes. Interbrand (1990) and Financial World (1998) regard the brand of future earnings as the foundation of brand equity evaluation and assert that the value of brand equity can be measured by a discount of the future cash flows[3]. Although this model is easier to understand and apply in practice, it only considers the financial elements and market factors while ignoring the factors of consumers; Kevin Lane Keller(2001) referred to brand equity as customer-based brand equity and build the consumer based brand equity (CBBE) model which involved four aspects: brand awareness, brand connotation, brand response and brand relationship; David Aaker(1993) who advocated evaluating brand equity with the perspective of consumers is known as a pioneer in this field. He has provided the most famous definition of brand equity and pointed that the brand equity has five dimensions. The weakness of the model is that it is difficult to carry out a quantitative analysis, it is just a qualitative analysis[4]; In view of the weakness of the customer-based brand valuation model, Fan Xiucheng (2000) proposed the "loyalty factor" assessment method which is an attempt to quantize the brand valuation model which is based on consumer, and it also has a certain directive function[5].

By reviewing the academic research on brand valuation methods, we can see that researchers have developed diverse models based on different perspectives. But, a comprehensive and systematical method which is integrated with financial factors, market factors and consumer factors 
is lacking. Most of the famous valuation methods lack the consideration of consumer factors, in this paper, we argue that customer perceptions is the source of brand equity[6]and consumer factors play an important role in the process of assessing the value of brand equity, so we build the optimized Interbrand approach which is based on consumer.

\section{THE BRIEF INTRODUCTION OF INTERBRAND MODEL}

Interbrand model is a financial-market-value-based technique for estimating a firm's brand equity, the essence of this method is a method which turns the future income to present value[7]. In this method, brand equity is defined as "the incremental cash flows which accrue to branded products over unbranded products". The two components of this model are brand-contributed revenue and brand strength multiple. The critical component of this method is how to convert the brand's future income into practical value. Interbrand uses the weighted average branded product revenue before taxes for the previous three years discounted for the earnings attributed to the brand. To be specific, the evaluation process can be divided into three steps: financial analysis, market analysis, brand strength analysis (The process is showed in figure 1).

1) Financial analysis. Through financial analysis, we can deprive intangible- assets-contributed revenue from the future revenue of branded product.

2) Market analysis. Through the Role of Branding Index (RBI), we can separate the brand-contributed revenue from the contributed revenue of other intangible assets, and the RBI varies from different industries.

3) Brand strength analysis. Brand strength is assessed from seven aspects: market leadership, brand stability, current market prospect, brand extension possibilities, internationalization potential, and adaptation to time, brand support and legal protection[8]. Interbrand group has developed a chart known as the "S-curve" to relate the brand strength and brand multiplier[9]. By calculating brand strength and utilizing the S-curve to transform it into brand multiplier, we can assess the risk of transforming the future contributed revenues of the brand into real income. (The S-curve is shown in Figure 2).

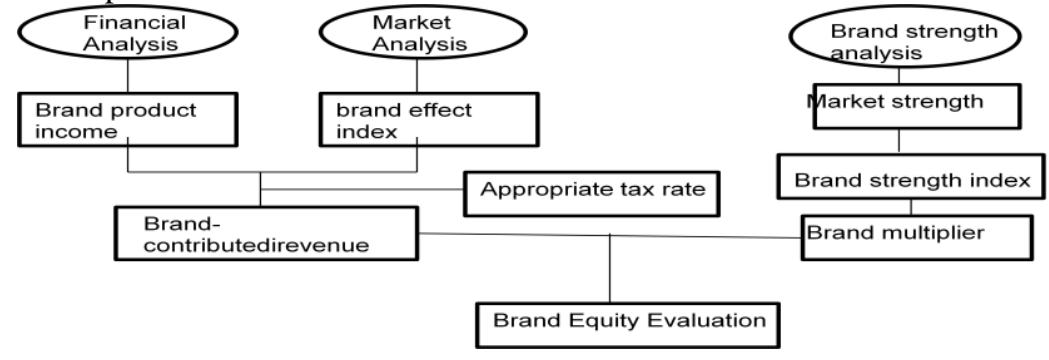

Figure 1. The interbrand brand model

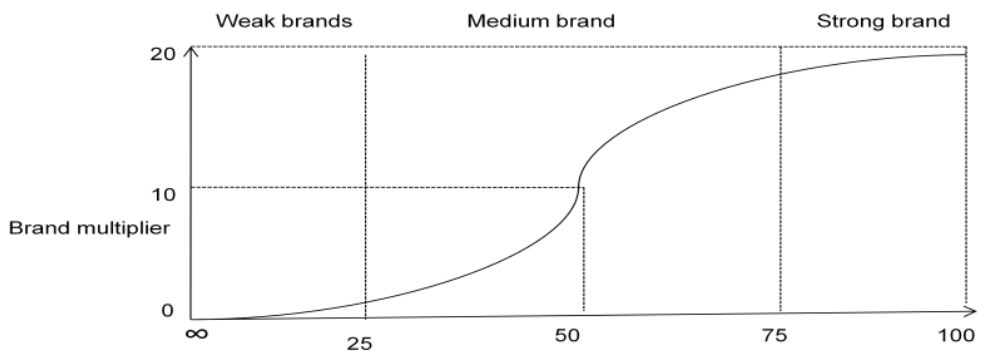

Figure 2. The S-curve of Interbrand model

Interbrand model as one of the global recognized and most comprehensive approach, it plays a significant role for the development of the study of brand equity evaluation. Although the Interbrand approach seems to be comprehensive, in our opinions it has its shortcomings:

1) The determination of RBI is too subjective[10]. RBI plays a central role in the process of separating brand-contributed revenue from other-intangible-assets. In the Intrebrand model, the determination of RBI is based on the expert's personal experience and historical data which may lead the result lacking of objectivity.
2) The brand-strength measurement system is not suitable for the characteristic of the China market. The objects of the model are relatively mature brands in the western market, if we don't take the developmental stage and characteristic of China brand into account, the deviation of brand evaluation will take place.

3) The model lacks of evaluating the brand equity from consumer's perspective. Although the model could be convenient to put into practice[11], the seven factors are measured from the financial perspective or market perspective, not including consumer perspective. We hold 
the opinion that ignoring consumer perspective in the process of measuring brand equity is not comprehensive.

\section{THE OPTIMIZED INTERBRAND MODEL BASED ON CONSUMER PERSPECTIVE}

In view of the shortcoming of Interbrand model, we argue that the evaluation model should focus on the source of brand equity. Brand equity as a kind of intangible assets which is objective existence, it attaches to customer perceptions rather than the product itself[12].So we add consumer elements into the new model. Compared to Interbrand model, the proposed model has the advantages of overcoming the weakness of Interbrand approach and trying to combine the consumer perspective and financial perspective together by attempting both to estimate the brand equity.

\section{A. The main Idea of the Optimized Model}

After revising and modifying several times, the optimized model which is based on Interbrand model is proposed. The new model can be expressed symbolically as Formulation (1).
$\mathrm{V}=\mathrm{G} \times \mathrm{S}$

Where:

$\mathrm{V}=$ brand equity

$\mathrm{G}=$ brand-contributed revenue

$\mathrm{S}=$ brand multiplier

The main differences between the optimized model and Interbrand model are as follows: in the original model, the brand effect index is determined by specialist which may lead to a high degree of subjectivity. On the contrary, we use the method of principal component analysis(PCA) to make sure the data remains objectivity in the optimized model; In Interbrand model, brand strength is determined by the single-factor of market-strength, while in the optimized model, it is measured by the optimized marketstrength index and the consumer-strength index; The optimized model adopts fuzzy comprehensive evaluation method to determine the weight and score of each index and ensure the objectivity of them.

The details of the optimized brand equity model can be expressed symbolically as follows:

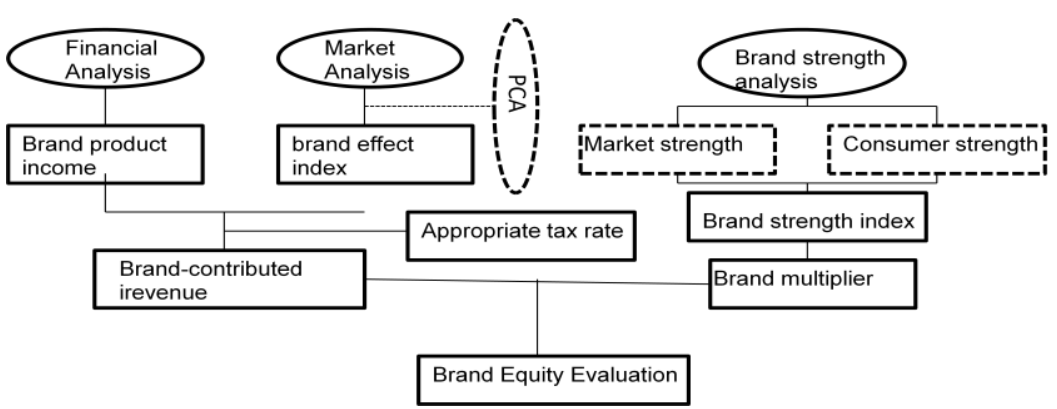

Figure 3. The optimized brand equity based on Interbrand model

\section{B. The Determination of Parameters in the Formula}

1). The determination of brand-contributed revenue: The brand-contributed revenue in the new model is similar to the meaning of brand revenue in the Interbrand model. Using the brand-contributed revenue of the latest three years and giving them different weights to forecast the brand-contributed income in the future. The formula is shown as follows:

$\mathrm{ABCR}=(\mathrm{BCRT} * 3+\mathrm{BCRL} * 2+\mathrm{BCRBL} * 1) /(1+2+$

Where:

$\mathrm{ABCR}=$ the average brand-contributed revenue

$\mathrm{BCRT}=$ the brand-contributed revenue this year

$\mathrm{BCRL}=$ the brand-contributed revenue last year

$\mathrm{BCRBL}=$ the brand-contributed revenue the year before last year

As for brand-contributed revenue, we determine it through the following steps: firstly, we calculate the overall benefits of intangible assets of the brand product by financial analysis. Secondly, through the principal component analysis, we can get the brand effect index of a certain industry and separate the brand-contributed income from other incomes which are contributed by other intangible assets (e.g. patented technology, management and other factors). Doing this can avoid the possibility of overestimating the value of brand equity. Finally, the brand-contributed revenue can be calculated by deducting the income taxes.

2). The determination of brand strength:In the proposed model, brand multiplier is determined by brand strength, and the score of brand strength and brand multiplier have a positive correlation. In the process of measuring the value of brand equity, if the brand strength gets a high score, we can use a large brand multiplier, while the weak brand is opposite[13].

a). Confirm the factor contribute to brand strength

In the new model, the factors which contribute to the brand strength are classified into two different categories: market strength and consumer strength. The revised market strength is described by 7 new indicators such as brand track, brand development patterns and so on. And, the consumer strength is determined by three factors which are 
brand awareness, brand attitude, brand behavior. All factors

Table 1.

which contribute to the brand strength are described in

TABLE 1 THE BRAND STRENGTH SYSTEM

\begin{tabular}{|c|c|c|c|}
\hline \multicolumn{3}{|c|}{ Factors } & Meaning \\
\hline \multirow{7}{*}{$\begin{array}{l}\text { Market } \\
\text { strength }\end{array}$} & \multirow{2}{*}{$\begin{array}{l}\text { Brand } \\
\text { history }\end{array}$} & Brand track & Whether the brand developmental path is steady \\
\hline & & $\begin{array}{l}\text { Brand development } \\
\text { patterns }\end{array}$ & The brand is built on advertising or technology \\
\hline & \multirow{3}{*}{$\begin{array}{l}\text { Brand } \\
\text { status }\end{array}$} & $\begin{array}{l}\text { Industry } \\
\text { characteristics }\end{array}$ & Whether the industry is mature, stable and highly competitive \\
\hline & & Market leadership & $\begin{array}{c}\text { Whether the branded product take the leading position in the industry } \\
\text { market }\end{array}$ \\
\hline & & Brand protection & Whether the enterprise attaches great importance to brand protection \\
\hline & \multirow{2}{*}{$\begin{array}{l}\text { Market } \\
\text { prospect }\end{array}$} & Brand support & Whether the brand is able to obtain sustained investment \\
\hline & & $\begin{array}{l}\text { Advantage } \\
\text { maintaining }\end{array}$ & Whether the brand product can maintain a sustainable competitive advantage \\
\hline \multirow{5}{*}{$\begin{array}{l}\text { Consumer } \\
\text { strength }\end{array}$} & \multirow{2}{*}{$\begin{array}{l}\text { Brand } \\
\text { recogniti } \\
\text { on }\end{array}$} & Brand awareness & Whether the brand has a higher brand awareness \\
\hline & & Brand association & Whether the brand has abundant and positive association \\
\hline & \multirow[b]{2}{*}{$\begin{array}{l}\text { Brand } \\
\text { attitude }\end{array}$} & Perceived quality & Whether the brand has better perceived quality \\
\hline & & $\begin{array}{l}\text { Brand reputation } \\
\text { /Brand } \\
\text { satisfaction }\end{array}$ & Whether the brand has good reputation among consumers \\
\hline & $\begin{array}{c}\text { Brand } \\
\text { behavior }\end{array}$ & Brand loyalty & Whether the consumer have brand loyalty \\
\hline
\end{tabular}

b). Quantify the brand strength:The following analysis is about how to determine brand strength in the new model. As a typical multi-factor comprehensive evaluation problem, the brand strength system in the proposed model has a multiple layers. Because of the difficulty of separating the contribution of different factors from each other and the brand evaluation index is hard to quantify, we use the fuzzy comprehensive evaluation method[14] to determine the weight of evaluation index and the score of brand strength in the proposed method.

The process of evaluating the brand strength can be divided into three steps: firstly,we appraise the grade-1 evaluation index by the fuzzy comprehensive evaluation method;secondly,we can get the result of grade- 2 evaluation index based on first step; finally, we can use the method which is similar to the second step and get the result of grade- 3 evaluation index. In the end, we can confirm the score of the brand strength. Owing to the limited space of this paper and the method of determining various indexes are similar to each other, we take the calculation process of brand history strength and market strength for example, and other indicators are similar to be determined.

1) First grade fuzzy comprehensive evaluation -- the calculation process of brand history strength

Factor sets. The evaluation factor set of brand history can be set as: $U_{1}=\left(u_{1}^{(1)}, u_{2}^{(1)}\right)$, where: $u_{1}^{(1)}=$ brandtrack $u_{2}^{(1)}=$ branddevelopmentpatterns.

Review sets. We set the review sets as: $\mathrm{V}=\left(\mathrm{v}_{1}, \mathrm{v}_{2}, \mathrm{v}_{3}, \mathrm{v}_{4}, \mathrm{v}_{5}\right)$, where: $v_{i}=$ evaluationresult , $\mathrm{i}=1,2 \ldots 5$, and,$V=$ (best, better, good,bad,worse).

Determine the weight of each evaluation factor. We assume that $A_{1}=\left(a_{1}^{(1)}, a_{2}^{(1)}\right)$ is the weight distribution set of $\mathrm{U}_{1}$, where: $\mathrm{a}_{1}^{(1)}+\mathrm{a}_{2}^{(1)}=1, a_{1}^{(1)} \geq 0, a_{2}^{(1)} \geq 0, a_{1}^{(1)}=$ theweightofbrandtrack on thebrandhistory , $a_{2}^{(1)}=$ theweig htofbranddevelopmentpatterns on thebrandhistory

- The weight distribution set is determined through questionnaire survey and expert discussion.

Construct the transformation matrix from $U_{1}$ to $V$. We can determine the transformation matrix through questionnaire survey and expert discussion .We define the transformation matrix is $\mathrm{R}_{1}$.

$r_{i j}^{(1)}$

$$
\text { Where: } R_{1}=\left[\begin{array}{lllll}
r_{11}^{(1)} & r_{12}^{(1)} & r_{13}^{(1)} & r_{14}^{(1)} & r_{15}^{(1)} \\
r_{21}^{(1)} & r_{22}^{(1)} & r_{23}^{(1)} & r_{24}^{(1)} & r_{25}^{(1)}
\end{array}\right]
$$

$$
=\frac{\text { the number of experts who choose } v_{j} \text { on the factor } u_{i}^{(1)}}{\text { the total number of experts }}
$$

And, $r_{i j}^{(1)}$ represents the corresponding relationships between $u_{i}^{(1)}$ and $v_{j}, \mathrm{i}=1,2 ; \mathrm{j}=1,2 \ldots 5 . j=1,2 \ldots 5$.

Construct first grade fuzzy comprehensive evaluation matrix. The first grade fuzzy comprehensive evaluation matrix can be build by $A_{1}=\left(a_{1}^{(1)}, a_{2}^{(1)}\right)$ and $R_{1}$.

$$
\mathrm{B}_{1}=\mathrm{A}_{1} \times \mathrm{R}_{1}=\left(\mathrm{b}_{1}^{(1)}, \mathrm{b}_{2}^{(1)}, \mathrm{b}_{3}^{(1)}, \mathrm{b}_{4}^{(1)}, \mathrm{b}_{5}^{(1)}\right)
$$

Similarly, we can get $B_{2}$ and $B_{3}$ :

$$
\begin{gathered}
\mathrm{B}_{2}=\left(b_{1}^{(2)}, b_{2}^{(2)}, b_{3}^{(2)}, b_{4}^{(2)}, b_{5}^{(2)}\right), \\
B_{3}=\left(b_{1}^{(3)}, b_{2}^{(3)}, b_{3}^{(3)}, b_{4}^{(3)}, b_{5}^{(3)}\right)
\end{gathered}
$$

2) Second grade fuzzy comprehensive evaluation -- the 
calculation process of market strength

Factor sets. The evaluation factor sets of market strength can be set as: $U=\left(u_{1}, u_{2}, u_{3}\right)$,

Where: $u_{1}=$ brandhistory, $u_{2}=$ brand status,$u_{3}=$ marketprospect.

Review sets. We set the review sets as: $\mathrm{V}=\left(\mathrm{v}_{1}, \mathrm{v}_{2}, \mathrm{v}_{3}, \mathrm{v}_{4}, \mathrm{v}_{5}\right)$, where: $v_{i}=$ evaluationresult , $\mathrm{i}=1,2 \ldots 5$, and,$V=$ (best, better, good, bad, worse).

Determine the weight of each evaluation factor. We assume that $A=\left(a_{1}, a_{2}, a_{3}\right)$ is the weight distribution set of $U$. Where: $a_{1}+a_{2}+a_{3}=1 ; a_{1} \geq 0, a_{2} \geq 0, a_{3} \geq$ $0, a_{1}=$

theweightofbrandhistory on themarketstrength , $a_{2}=$

theweightofbrandstatus on themarketstrength, $a_{3}=$ the weight of market prospect on the market strength.

The weight distribution set is determined by questionnaire survey and expert discussion.

Construct the transformation matrix from $U$ to $V$. Through the result of first grade fuzzy comprehensive evaluation, we can construct the fuzzy transition matrix from $U$ to $V$. We define the matrix is $R$.

$$
R=\left[\begin{array}{ccccc}
b_{1}^{(1)} & b_{2}^{(1)} & b_{3}^{(1)} & b_{4}^{(1)} & b_{5}^{(1)} \\
b_{1}^{(2)} & b_{2}^{(2)} & b_{3}^{(2)} & b_{4}^{(2)} & b_{5}^{(2)} \\
b_{1}^{(3)} & b_{2}^{(3)} & b_{3}^{(3)} & b_{4}^{(3)} & b_{5}^{(3)}
\end{array}\right]
$$

Construct second grade fuzzy comprehensive evaluation matrix. We can construct second grade fuzzy comprehensive evaluation model by $A=\left(a_{1}, a_{2}, a_{3}\right)$ and $R$.

$$
B=A \times R=\left(b_{1}, b_{2}, b_{3}, b_{4}, b_{5}\right)
$$

3) Calculate the score of market strength and consumer strength.

Through consulting the expert advice, we assume the score of each element are $v_{1}=100, v_{2}=85, v_{3}=70, v_{4}=$ $55, v_{5}=40$. So we can get the score of market strength is $\mathrm{N}_{1}=\mathrm{B} \times \mathrm{V}^{\mathrm{T}}$. Following the above steps, we can get the consumer strength $N_{2}$.

4) Calculate the score of brand strength

Through the score of market strength and consumer strength, we can get the score of brand strength. The formula of determining the score of brand strength is

$$
N=k_{1} N_{1}+k_{2} N_{2} \quad \text {.Where: } \quad k_{1}=
$$
theweightofmarketstrength on thebrandstrength, $k_{2}=$ theweig htof consumerstrength on thebrandstrength . And the weight distribution set is determined by questionnaire survey and expert discussion.

5) Translate the score of brand strength into brand multiplier

Utilizing the S-curve, we can transform the score of brand strength into brand multiplier which is represented by $S$.

6) Determine the value of brand equity

So far, we have determined the brand-contributed revenue and brand multiplier. Through the formulation (1), we can determine the value of brand equity.

\section{V.SUMMARY AND CONCLUSIONS}

In order to test accuracy of the new model, we take Haier brand as an example to make an empirical analysis of the optimized model. Using the new model, we calculate the value of Haier brand equity is 15.34 billion yuan. However, according to the list, Top 500 Most Valuable Chinese Brands 2012 which is released by World Brand Lab, Haier is now valued at 82.529 billion yuan. Recently, Interbrand Group release a report which is named Best Chinese Brands 2012, it shows that the value of Haier brand equity reaches 4.833 billion yuan. Thus, the result of proposed model is quite differences from the above method. In reference to Haier's stock market price of 33.69 billion yuan (March 2013), it shows that the result of new model is more reasonable.

The purpose of proposed model is not to determine which method is more scientific, but to put forward a new idea in brand evaluation. The principal contribution of our research is that it enriches consumer-based brand equity measurement and provides empirical analysis of the new model. By the literature review, we can see that there is not a comprehensive and systematical method which is integrated with financial factors, market factors and consumer factors and an instrument to measure brand equity from a customer perspective has been lacking. In this paper, the proposed model has the advantages of overcoming the weakness of Interbrand approach and combining the consumer perspective and financial perspective together by attempting both to estimate the brand equity and show the sources of value.

Another contribution of our paper is the confirmation of factors which contribute to the brand strength and the identification of the sources of brand equity. In the new model, we synthesized the factors proposed by Interbrand Group and Aaker. The factors are classified into two different categories: market strength and consumer strength. The revised market strength is described by 7 new indicators such as brand track,brand development patterns and so on. The consumer strength is determined by three factors which are brand awareness, brand attitude, brand behavior. Showing the composition of brand equity is helpful for the enterprise to have a deep understanding of brand concept and enhance the perceived quality of their service in order to positively impact customer satisfaction, which will in effect contribute towards enhanced brand equity.

\section{REFERENCES}

[1] Motameni R, Shahrokhi M. Brand equity valuation: a global perspective[J]. Journal of product \& brand management, 1998, 7(4) 275-290.

[2] Ambler T. Marketing and the bottom line: the marketing metrics to pump up cash flow[M]. Ft Pr, 2003. 
[3] Wang Chengjun.Discussions on the approaches taken by financial world for Appraising Brand-Name. The Journal of Assets Appraisal, 2001(6):25-27.

[4] Ruževičiūtė R, Ruževičius J. Brand equity integrated evaluation model: consumer-based approach $[\mathrm{J}]$. Economics and Management, 2010, 15: 719-725.

[5] Fan Xiucheng and Ling Yan Loyalty Factor Method of Brand Valuation[J]. Scientific Management Research, 2000,5(18):23-25.

[6] Keller K L. Conceptualizing, measuring, and managing customer-based brand equity[J]. The Journal of Marketing, 1993: $1-22$.

[7] Fu Guoqun.The comment of Interbrand Brand Evaluation Method [J]. Foreign Economies \& Management, 1999(11):37-41.

[8] Zhang Jinxin.A Simple Model of Optimized Brand Value Evaluation [J]. Journal of Shanxi University of Science \& Technology (Natural Science Edition), 2010, 28(4):123-127.
[9] Soto T. Methods for Assessing Brand Value: A Comparison Between the Interbrand Model and the BBDO's Brand Equity Evaluator Model[M]. Bod, 2008.

[10] Zhang Qian(2006).Study on Brand Value Appraisal Method. Northeastern University, 2006.

[11] Wang Chengrong. Valuation and Management of Brand Value.Beijing : China Renmin University Press,2006.

[12] Lassar, W., Mittal, B., \& Sharma, A. (1995).Measuring customer-based brand equity. Journal of consumer marketing, 12(4), 11-19.

[13] Huang Heshui\&PengDanling. A Cognitive Model of Brand Equity[J].Advances in Psychological Science, 2002,10(3):350-35.

[14] Wang Chengrong. Valuation and Management of Brand Value.Beijing : China Renmin University Press,2006(In Chinese)

[15] Guan Zhijun\&ShuJunyi .Evaluation model for dissertation review and its application[J].Science research management,2005,(3):153-157. 